\title{
Qualidade com Equidade Escolar: Obstáculos e Desafios na Educação Brasileira
}

\author{
Quality with Equity in Schools: Obstacles and Challenges in \\ Brazilian Education
}

\author{
Rodrigo Travitzki * \\ Universidade de São Paulo
}

\begin{abstract}
Este trabalho investiga a qualidade com equidade nas escolas brasileiras, um desafio atualmente importante no que se refere ao papel da educação em uma sociedade desigual. A comparação entre os resultados dos três ciclos da Educação Básica (5o ano, 90 ano e 3a série) foi realizada com regressão linear e revelou uma diminuição sistemática da equidade de resultado ao longo da escolaridade. A modelagem multinivel foi realizada para o 90 ano das 11.810 escolas públicas de seis estados brasileiros, três de alta renda per capita (Rio Grande do Sul, Santa Catarina e São Paulo) e três de baixa renda per capita (Alagoas, Ceará e Maranhão). Os indicadores escolares de qualidade e equidade de resultado apresentaram correlação negativa $(\mathrm{r}=-0,58)$. Do total, $41 \%$ das escolas apresentou qualidade acima da mediana nas duas provas do Saeb (Matemática e Língua Portuguesa) e 6\% também apresentou equidade de resultado acima da mediana, constituindo-se no seleto grupo de escolas capazes de ensinar bem e a todos. Os resultados sugerem que a qualidade com equidade é de fato um desafio na educação pública. Para se atingir tal objetivo, são especialmente importantes: valorização salarial de professores e diretores; experiência dos diretores; atuação criativa do professor; disponibilidade de recursos pedagógicos para o professor; ambiente escolar seguro com espaço de convivência. Em relação às políticas públicas, os resultados sugerem necessidade de valorização material e imaterial dos profissionais da educação, especialmente em contextos de grande desigualdade e recente expansão da rede pública.
\end{abstract}

Palavras-chave: Educação pública, Qualidade educacional, Igualdade de oportunidades, Indicadores educacionais, Equipamento educacional.

This paper investigates quality with equity in Brazilian schools, an important current challenge for the role of education in an unequal society. The comparison between results of the three cycles of basic education (5th, 9th and 12th grades) revealed a systematic decrease in equity throughout schooling. Multilevel modeling was conducted for the ninth year of 11,810 public schools in six Brazilian states, three of high per capita income (Rio Grande do Sul, Santa Catarina and São Paulo) and three of low per capita income (Alagoas, Ceará and Maranhão). The school indicators of effectiveness and equity showed a negative correlation $(\mathrm{r}=-$ 0.58). We found $41 \%$ of schools with effectiveness above the median in both Saeb assessments and $6 \%$ also showed equity above the median in both tests. The results suggest that quality with equity is indeed a challenge. In order to achieve this objective, the following are especially important: salary appreciation of teachers and principals; principals experience; creative teaching; availability of teaching resources for the teacher; safe school environment with common areas. Regarding public policies, the results suggest the need for material and immaterial valuation of education professionals, especially in contexts of great inequality and recent expansion of the public education system.

Keywords: Public education, Educational quality, Equal opportunity, Educational indicators, Educational equipment.

*Contacto: travitzki@usp.br

ISSN: $1696-4713$

www.rinace.net/reice/

revistas.uam.es/reice
Recibido: $\quad 21$ de abril 2017

$1^{\text {a }}$ Evaluación: 27 de mayo 2017

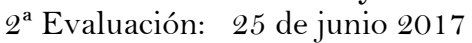

Aceptado: 1 de julio 2017 


\section{Introdução}

A educação é um dos pilares da democracia, supostamente responsável, dentre outras finalidades, por criar condições para que os mais jovens possam praticar certo tipo de experiência comunicada que os habilite a viver em um mundo plural e democrático (Dewey, 2004). Embora haja expectativa de que a universalização da escola possa promover uma distribuição de saberes mais igualitária entre os cidadãos do que a distribuição de riquezas, desde meados do século passado acumulam-se evidências de que a escola tem um alcance muito limitado como agente desta mudança na sociedade (Bourdieu e Passeron, 1990; Coleman et al., 1966).

Em virtude da grande influência das condições familiares no desempenho escolar (Travitzki, Calero e Boto, 2014), torna-se preciso superar um tipo especial de desigualdade: a iniquidade. Na educação, a equidade apresenta dois aspectos importantes e interligados: a igualdade de oportunidades (evitar que condições pessoais, como gênero e nível socioeconômico, sejam um obstáculo para o sucesso escolar) e a inclusão (a garantia de padrões mínimos de educação para todos) (Field, Kuczera e Pont, 2007).

Contudo, apenas equidade não basta, é preciso também excelência, pois não é desejável que todos sejam igualmente pouco educados. Em que medida estes dois objetivos são compatíveis entre si? Que tipo de política pública poderia ser capaz de promover ambos simultaneamente? Neste trabalho, investigamos tais questões com base nos dados oficiais do Brasil -o Sistema de Avaliação da Educação Básica (SAEB). Partimos de uma concepção de eficácia escolar que inclui qualidade e equidade de resultados, além de desenvolvimento integral.

Buscamos, mais especificamente, respostas às perguntas:

- A influência do nível socioeconômico familiar no desempenho dos alunos vai diminuindo ao longo da vida escolar?

- Existem escolas que ensinam os alunos de forma mais equitativa do que outras?

- Existem escolas que ensinam os alunos de forma equitativa e com qualidade?

- Se sim, é possível identificar características associadas a estas escolas?

- Em que medida os dados do Saeb podem ser utilizados para avaliar a eficácia escolar?

Há diversos trabalhos sobre o tema da qualidade com equidade no Brasil. O estudo de Soares (2005) apresenta aspectos semelhantes a este, porém utilizando indicadores de qualidade e equidade separadamente com dados amostrais. A contribuição deste trabalho reside no uso simultâneo dos dois indicadores em dados censitários, com objetivo de investigar a excelência com equidade, identificando também possibilidades e limites tanto nos indicadores quanto nos dados disponíveis.

\section{Fundamentação teórica}

\subsection{Eficácia escolar}

A eficácia é uma condição necessária, porém não suficiente, para a qualidade na educação, quando consideramos o conceito de "qualidade" em um sentido mais amplo (Martínez- 
Garrido e Murillo, 2016). Os primeiros estudos em larga escala sobre eficácia escolar revelaram uma surpreendente incapacidade das escolas em superar as desigualdades socioeconômicas que as rodeiam (Coleman, 1966), confirmando assim, em certa medida, a ideia de que a estrutura escolar, mais do que proporcionar a distribuição de saberes, reproduz as desigualdades existentes na sociedade (Bourdieu e Passeron, 1990). Desde então, diversos pesquisadores têm se dedicado a compreender esta limitação e os possíveis caminhos para superá-la, criando conceitos como "efeito escola" e "eficácia escolar". Alguns desses estudos são menos "pessimistas" do que os primeiros, sugerindo que a escola faz alguma diferença - mesmo em termos de testes padronizados - (entre 5 e $35 \%$ da variância) através de suas práticas pedagógicas, do clima de aprendizagem, dentre outras características (Martínez-Arias, Gaviria e Castro, 2009). Outros estudos buscam identificar os fatores mais relevantes para eficácia escolar, como liderança profissional, objetivos compartilhados, altas expectativas, reforço positivo, monitoramento do progresso, direitos e deveres dos alunos, parceria com a família (Sammons, Hillman e Mortimore, 1995). No caso da educação inclusiva, potencialmente promotora de equidade, há evidências de que algumas competências docentes são especialmente importantes, tais como o planejamento estratégico, a inovação e a criatividade (Fernández Batanero, 2013). O debate sobre a eficácia da rede escolar como promotora de excelência e equidade nas democracias continua sendo um terreno fértil.

Em busca de indicadores de eficácia escolar que pudessem articular excelência e equidade, Mortimore (1991) resgatou o conceito econômico de "valor adicionado", definindo assim a escola eficaz como aquela "em que os estudantes progridem mais do que seria esperado considerando suas condições de entrada” (p. 9, tradução nossa). Adicionando mais um ingrediente a esta definição, a escola eficaz seria aquela capaz de promover "um desenvolvimento integral de todos e cada um de seus alunos maior do que seria esperado levando em conta seu rendimento prévio e a situação social, econômica e cultural das famílias" (Murillo, 2003, pp. 2-3, tradução nossa).

No contexto da América Latina, este conceito foi um dos referenciais teóricos de um amplo estudo sobre fatores associados à eficácia escolar (Murillo, 2008). Destacamos, deste amplo estudo, um artigo de Román (2008), que realizou modelagem multinivel em uma abordagem de valor adicionado, e concluiu que há três grandes fatores nas salas de aula que interferem diretamente no aprendizado: o clima de aula (por exemplo, acolher interesses e promover participação dos alunos, estabelecer regras justas), a metodologia didática (por exemplo, um repertório variado de atividades e recursos didáticos) e a gestão do tempo das aulas (por exemplo, maximizando o tempo destinado a atividades pedagógicas). Foram identificados também fatores indiretos, como o planejamento de ensino, disponibilidade e adequação de recursos, participação da família e algumas características dos professores.

No contexto ibero-americano, vale destacar um trabalho mais recente de MartínezGarrido e Murillo (2016) -também com modelagem multinivel e valor adicionado- com objetivo de elaborar um modelo ibero-americano de ensino eficaz. O estudo identificou dez fatores relacionados ao ensino eficaz: 1) tempo e oportunidades de aprendizagem; 2) clima de aula; 3) metodologia docente; 4) deveres escolares; 5) atenção à diversidade; 6) expectativas quanto ao estudante; 7) implicação familiar; 8) trabalho em equipe; 9) distribuição do tempo docente; 10) condições laborais. $O$ estudo se fundamenta no conceito de escola eficaz de Murillo (2003) e Martínez-Garrido (2015) tendo, porém, 
adicionado um quarto ingrediente. $\mathrm{O}$ ensino eficaz congrega, nesta perspectiva, quatro características:

- Desenvolvimento integral: promove tanto o desenvolvimento sócio afetivo quanto o cognitivo e o psicomotor.

- Equidade: promove o desenvolvimento de todos e cada um dos estudantes.

- Perdurabilidade dos efeitos: em que medida os efeitos benéficos vão para além do curso ou etapa de ensino.

- Valor adicionado: em que medida a aprendizagem dos alunos foi promovida pelo trabalho docente em sala de aula.

Neste trabalho, partimos desta concepção de ensino eficaz como referencial teórico para a investigação da eficácia escolar. Por limitações dos dados disponíveis, a perdurabilidade dos efeitos não foi incluída no modelo.

Vale ressaltar ainda que os estudos sobre valor adicionado pressupõem a existência de dados longitudinais e, opcionalmente, dados contextuais sobre a escola e os alunos. Por este motivo, as estimativas que não dispõem de pelo menos duas medidas por aluno são hoje reunidas sob a alcunha de "modelos de desempenho contextualizado", para se diferenciarem dos "modelos de valor adicionado" (Ferrão, 2013). O objetivo, seja qual for a metodologia, é proporcionar maior comparabilidade entre o desempenho de alunos com características e contextos muito diferentes. Com isso, é possível identificar, por exemplo, instituições que realizam um bom trabalho, mesmo partindo de condições desfavoráveis. Estimativas com dados brasileiros sugerem que 20\% das escolas mal avaliadas nos rankings oficiais apresentam desempenho contextualizado positivo (Travitzki, Calero e Boto, 2014). Ou seja, elas realizam um trabalho acima do esperado, mas são desvalorizadas por políticas de ranqueamento com base em desempenho médio.

\subsection{Qualidade e equidade nas escolas brasileiras}

A igualdade de oportunidades é ainda um objetivo distante no Brasil. Estimativa com dados do Saeb aponta que seria necessário aumentar em sete vezes o gasto por aluno nas escolas mais pobres, para que pudessem se equiparar às mais ricas (Waltenberg e Vandenberghe, 2007). Há também evidências de grande desigualdade entre escolas no que se refere à infraestrutura, especialmente entre as regiões Norte e Nordeste e o resto do país (Soares-Neto et al., 2013).

Os primeiros estudos sobre efeito escola no Brasil foram publicados no final da década de noventa (Ferrão e Fernandes, 2003), com base nos dados provenientes do Saeb. Uma análise em painel, publicada pelo Inep (Instituto Nacional de Estudos e Pesquisas Educacionais Anísio Teixeira) identificou características escolares associadas ao desempenho no Saeb (Biondi e Felício, 2007). Algumas das características sugerem necessidade de valorização efetiva da carreira docente (menor rotatividade dos professores e mais experiência de trabalho) além da importância de o professor utilizar o computador como recurso pedagógico. Mais recentemente, foram analisados dados do Saeb 2001 e $2011 \mathrm{em}$ uma tese que define equidade a partir da oportunidade de um aluno ter professores mais qualificados (Simielli, 2015). Foi utilizado um modelo logístico para descrever esta oportunidade. A autora aponta, ao final, três pilares da equidade na educação: 1) padrões mínimos de recursos e processos; 2) discriminação positiva (o favorecimento dos menos favorecidos); 3) investimento nos professores. 
Em outro trabalho, pesquisadores aplicaram o conceito de equidade na educação brasileira de diferentes formas (Albernaz, Ferreira e Franco, 2002). Operacionalmente, ela está vinculada ao coeficiente de alguma variável explicativa -sendo que às vezes se observa seu efeito fixo e às vezes o efeito aleatório- dependendo do caso. Conceitualmente, eles definiram a equidade em termos do desempenho diferencial entre grupos de diferentes: 1) gêneros; 2) raças; 3) níveis socioeconômicos. Foi ajustado um modelo de dois níveis (aluno e escola) com uma variável de coeficiente aleatório (o indicador de Nível Sócio Econômico (NSE) do aluno) no nível da escola. Tal modelo fornece um indicador de qualidade (o intercepto no nível da escola) e um indicador de equidade (o coeficiente aleatório do NSE). Abordagem semelhante é utilizada neste trabalho.

Com efeito, Albernaz e colegas obtiveram dois indicadores de resultado, que testaram separadamente como variáveis resposta de modelos de regressão para cada característica da escola. Diversas variáveis se mostraram vinculadas à qualidade (intercepto), porém poucas à equidade (inclinação): apenas a escolaridade e o salário dos professores.

Seguindo esta linha metodológica, porém utilizando dados de Belo Horizonte (MG), Soares e Andrade (2006) chegaram à conclusão de que, embora existam escolas que consigam ensinar também os menos favorecidos, o sistema de educação do município "só consegue produzir qualidade na presença de alta iniquidade" (p. 107).

Cabe ainda destacar outro estudo de Soares em que são apresentadas evidências, com base na prova de matemática do $9^{\circ}$ ano do Saeb 2001, de que há problemas de qualidade e equidade que precisam ser solucionados paralelamente (Soares, 2005). Diversas variáveis de processo (características do professor e da escola) foram testadas quanto à relação com qualidade e equidade separadamente (foram analisados dois tipos de equidade no estudo citado: relativa à cor da pele e relativa ao NSE). A maioria das variáveis apresenta relação significativa no primeiro caso, mas no segundo elas são poucas e de difícil interpretação. Tal resultado sugere que os indicadores de equidade não fazem muito sentido isoladamente. Afinal, uma escola igualmente ineficaz para todos os alunos seria considerada equitativa. Com efeito, neste trabalho utilizamos um indicador de equidade junto a um indicador de qualidade.

\section{Métodos}

\subsection{Enfoque de investigação}

Partimos da concepção de escola eficaz descrita por Murillo (2003). Embora seja difícil concretizar tal modelo, realizamos um estudo exploratório nesse sentido, utilizando os dados do Saeb. Com isso, buscamos discutir as possibilidades e limitações tanto dos indicadores de eficácia escolar, quanto da Prova Brasil como fonte de informação para esta finalidade. Além disso, buscamos identificar algumas características associadas às escolas eficazes.

\subsection{Desenho de investigação}

Com objetivo de investigar as condições associadas à eficácia escolar, ajustamos modelos multinivel para os dados da Prova Brasil, o extrato censitário do Saeb. Tais modelos forneceram indicadores de qualidade e equidade para cada escola, a partir dos quais 
identificamos grupos de escolas potencialmente eficazes. Comparamos, então, tais escolas com as demais, analisando isoladamente 44 variáveis com testes de Wilcoxon.

Os dados foram integralmente coletados e processados com o auxílio do software de estatística R.

\subsection{Amostra utilizada}

Utilizamos os dados desagregados do Saeb 2011 e uma variável ${ }^{1}$ do Saeb 2013, totalizando 8.262.863 alunos. A análise multinivel se limitou a um subgrupo destes dados: os alunos do $9^{\circ}$ ano do Ensino Fundamental de escolas públicas de seis estados brasileiros. Ou seja, os dados da Prova Brasil relativos às seguintes Unidades Federativas (UF): Alagoas, Ceará, Maranhão, Rio Grande do Sul, Santa Catarina e São Paulo. Três UF correspondem às de menor rendimento nominal mensal domiciliar per capita do país (que doravante chamaremos de "pobres") enquanto as outras três (as "ricas") estão no extremo oposto (IBGE, 2014).

Esta amostra totalizou 1.010.381 alunos, com média de 244,7 pontos na prova de Matemática e 239,5 pontos em Língua Portuguesa, além de escolaridade familiar média de 7 anos, o que corresponderia ao Ensino Fundamental incompleto. Uma caracterização mais detalhada da amostra se encontra no quadro 1.

\subsection{Análise dos dados}

Inicialmente, foi estimada a associação entre o nível socioeconômico da família e o desempenho dos alunos nas três etapas de ensino, utilizando regressão linear e considerando a escolaridade familiar como proxy do nível socioeconômico. Trata-se, porém de uma abordagem metodologicamente limitada, de caráter exploratório.

A modelagem multinível foi aplicada apenas ao $9^{\circ}$ ano. Modelos de três níveis (aluno, turma e escola) foram ajustados em cada uma das seis UF. A modelagem multinível é considerada uma técnica estatística adequada para lidar com dados hierárquicos (Raudenbush e Willms, 1995), nos quais os agrupamentos interferem significativamente nos resultados individuais, tais como escolas e alunos. Os modelos multinível são ampliações dos modelos lineares clássicos, ajustando diversos submodelos para cada nível e permitindo que se analise as relações dentro de um nível e entre os níveis (Martínez-Garrido e Murillo, 2013).

Os modelos que ajustamos têm como variável resposta a nota do aluno em Matemática ou Língua Portuguesa, sendo as variáveis explicativas: $\left(\mathrm{x}_{1}\right)$ a escolaridade média dos pais do aluno, um proxy para o NSE do aluno - e ( $\mathrm{x}_{2}$ ) o NSE da escola (Saeb 2013). Incluiu-se também um efeito aleatório no coeficiente da variável $\mathrm{x}_{1}$ ao nível da escola, para estimar a equidade intraescolar.

1 O nível socioeconômico da escola, que foi considerado neste trabalho como uma variável ordinal. 
Quadro 1. Características das escolas agregadas por estado

\begin{tabular}{|c|c|c|c|c|c|c|c|c|c|c|c|c|}
\hline & \multicolumn{2}{|c|}{ Alagoas } & \multicolumn{2}{|c|}{ CEARÁ } & \multicolumn{2}{|c|}{ MARANHÃO } & \multicolumn{2}{|c|}{$\begin{array}{c}\text { SANTA } \\
\text { CATARINA } \\
\end{array}$} & \multicolumn{2}{|c|}{$\begin{array}{c}\text { SÃo } \\
\text { PAULO }\end{array}$} & \multicolumn{2}{|c|}{$\begin{array}{c}\text { RIO GRANDE } \\
\text { DO SUL }\end{array}$} \\
\hline Total de alunos & \multicolumn{2}{|c|}{42.572} & \multicolumn{2}{|c|}{99.460} & \multicolumn{2}{|c|}{67.666} & \multicolumn{2}{|c|}{80.435} & \multicolumn{2}{|c|}{611.227} & \multicolumn{2}{|c|}{109.021} \\
\hline Total de turmas & \multicolumn{2}{|c|}{1.202} & \multicolumn{2}{|c|}{3.341} & \multicolumn{2}{|c|}{2.219} & \multicolumn{2}{|c|}{3.199} & \multicolumn{2}{|c|}{18.190} & \multicolumn{2}{|c|}{4.360} \\
\hline Total de escolas & \multicolumn{2}{|c|}{482} & \multicolumn{2}{|c|}{1.569} & \multicolumn{2}{|c|}{1.202} & \multicolumn{2}{|c|}{1.352} & \multicolumn{2}{|c|}{4.983} & \multicolumn{2}{|c|}{2.236} \\
\hline \multirow[t]{3}{*}{$\underline{\text { Renda Mensal }(\mathrm{R} \$)^{*}}$} & 60 & & 61 & & 46 & & 1.2 & & 1.4 & & 1.3 & \\
\hline & \multicolumn{12}{|c|}{ CARACTERÍSTICAS DAS ESCOLAS POR ESTADO } \\
\hline & Me & DP & Me & DP & Me & DP & $\mathrm{Me}$ & DP & Me & DP & Me & DP \\
\hline $\begin{array}{l}\text { Total de alunos por } \\
\text { escola }\end{array}$ & 88,3 & 67,3 & 63,5 & 52,2 & 56,9 & 41,7 & 59,5 & 34,1 & 122,7 & 65,8 & 48,8 & 26,9 \\
\hline $\begin{array}{l}\text { Escolaridade familiar } \\
\text { média (anos) }\end{array}$ & 4,7 & 1,5 & 5,2 & 1,5 & 5,7 & 1,9 & 7,0 & 1,6 & 7,4 & 1,3 & 7,4 & 1,7 \\
\hline Média de Matemática & 219,2 & $14,4 \mathrm{C}$ & 235,6 & 18,7 & 218,6 & 18,5 & 257,4 & 17,1 & 247,2 & 16,2 & 258,8 & 19,4 \\
\hline A escola é fechada?** & $70 \%$ & $46 \%$ & $80 \%$ & $40 \%$ & $68 \%$ & $47 \%$ & $70 \%$ & $46 \%$ & $83 \%$ & $37 \%$ & $72 \%$ & $45 \%$ \\
\hline $\begin{array}{l}\text { Existe Conselho } \\
\text { Escolar? }\end{array}$ & $90 \%$ & $30 \%$ & $96 \%$ & $19 \%$ & $81 \%$ & $39 \%$ & $83 \%$ & $37 \%$ & $100 \%$ & $4 \%$ & $92 \%$ & $27 \%$ \\
\hline \multicolumn{13}{|l|}{ Diretor } \\
\hline $\begin{array}{l}\text { Experiência como } \\
\text { diretor (anos) }\end{array}$ & 6,2 & 5,7 & 8,0 & 6,2 & 8,5 & 7,2 & 6,2 & 5,5 & 11,3 & 8,2 & 7,8 & 6,1 \\
\hline Escolaridade (anos) & 14,8 & 0,9 & 14,9 & 0,7 & 14,6 & 1,1 & 14,9 & 0,6 & 15,0 & 0,5 & 14,9 & 0,5 \\
\hline Idade Máxima (anos) & 45,7 & 9,1 & 44,7 & 9,0 & 45,3 & 10,1 & 47,0 & 8,0 & 50,9 & 9,5 & 48,9 & 8,8 \\
\hline $\begin{array}{l}\text { Renda Familiar } \\
\text { Máxima }\end{array}$ & 7,3 & 3,5 & 6,7 & 3,9 & 6,3 & 3,6 & 11,1 & 3,7 & 11,7 & 3,7 & 9,2 & 3,9 \\
\hline Salário Máximo & 4,7 & 2,0 & 4,7 & 2,7 & 4,3 & 2,4 & 8,1 & 2,9 & 8,8 & 3,3 & 6,1 & 2,9 \\
\hline \multicolumn{13}{|l|}{ Professor } \\
\hline Escolaridade (anos) & 14,6 & 0,8 & 14,7 & 0,6 & 14,4 & 1,1 & 14,8 & 0,5 & 14,9 & 0,3 & 14,7 & 0,6 \\
\hline Idade (anos) & 42,5 & 5,8 & 41,2 & 5,9 & 41,9 & 6,3 & 43,2 & 5,9 & 45,6 & 5,8 & 45,1 & 6,8 \\
\hline Salário Máximo & 3,9 & 2,1 & 3,3 & 1,8 & 4,0 & 2,1 & 4,5 & 2,0 & 5,8 & 2,7 & 4,4 & 2,6 \\
\hline $\begin{array}{l}\text { Salário Máximo nessa } \\
\text { escola }\end{array}$ & 3,0 & 1,6 & 2,8 & 1,4 & 2,7 & 1,5 & 4,2 & 1,6 & 4,6 & 1,7 & 3,4 & 2,0 \\
\hline \multicolumn{13}{|l|}{ Uso de recursos } \\
\hline Copiadora & $64 \%$ & $38 \%$ & $83 \%$ & $30 \%$ & $50 \%$ & $40 \%$ & $92 \%$ & $18 \%$ & $72 \%$ & $33 \%$ & $95 \%$ & $16 \%$ \\
\hline Livro & $73 \%$ & $24 \%$ & $80 \%$ & $22 \%$ & $79 \%$ & $24 \%$ & $82 \%$ & $20 \%$ & $74 \%$ & $23 \%$ & $80 \%$ & $25 \%$ \\
\hline Slides/datashow & $45 \%$ & $35 \%$ & $50 \%$ & $38 \%$ & $33 \%$ & $35 \%$ & $53 \%$ & $31 \%$ & $41 \%$ & $31 \%$ & $46 \%$ & $35 \%$ \\
\hline
\end{tabular}

Nota: Me=média, DP=Desvio Padrão. As variáveis financeiras têm como unidade o salário mínimo, com exceção da Renda Mensal dos estados. * A Renda Mensal dos estados corresponde ao rendimento nominal mensal domiciliar per capita, segundo o IBGE 2014. ** Se refere à pergunta: há muros, grades ou cercas em condições de garantir a segurança dos alunos? Fonte: Elaborado com dados da Prova Brasil 2011, 9o ano do Ensino Fundamental.

O modelo, ajustado de forma independente para cada UF, é representado pelas equações (1) e (2).

$$
\begin{aligned}
& Y_{i j k}=\beta_{0}+\beta_{1 k} x_{1 i j k}+\beta_{2} x_{2 k}+u_{j}+u_{0 k}+e_{i j k} \\
& \beta_{1 k}=\beta_{1}+u_{1 k}
\end{aligned}
$$

Sendo que:

$\mathrm{Y}_{\mathrm{ijk}}$, desempenho do aluno i, pertencente à turma j e à escola k;

$\mathrm{x}_{1 \mathrm{jik}}$, escolaridade média (em anos) dos pais do aluno i, pertencente à turma j e à escola k; 


\title{
R. Travitzki
}

\author{
x $\mathrm{x}_{2 \mathrm{k}}$, nível socioeconômico da escola k; \\ $\mathrm{u}_{\mathrm{j}}, \mathrm{u}_{\mathrm{ok}}$, efeitos aleatórios nos respectivos níveis; \\ $\mathrm{u}_{1 \mathrm{k}}$, efeito aleatório no coeficiente da variável $\mathrm{x}_{1}$; \\ $\beta_{1}, \beta_{2}$, coeficientes fixos; \\ $\beta_{1 \mathrm{k}}$, coeficiente da variável $\mathrm{x}_{1}$, que varia entre as diferentes escolas.
}

O indicador de eficácia escolar corresponde ao efeito aleatório no nível da escola $\left(\mathrm{u}_{\mathrm{ok}}\right)$, enquanto o indicador de equidade corresponde ao efeito aleatório $\left(\mathrm{u}_{1 \mathrm{k}}\right)$. Foram ajustados, ao todo, 36 modelos. Para cada nota do Saeb (MT e LP) em cada um dos seis estados, foram ajustados três tipos de modelo: a) modelo nulo (com três níveis mas sem variáveis explicativas); b) modelo de componentes de variância (incluindo as duas variáveis explicativas como efeitos fixos); c) modelo de coeficientes aleatórios (incluindo o efeito aleatório no coeficiente da variável $\mathrm{x}_{1}$ ). Os coeficientes de Correlação Intra Classe foram estimados com base no modelo (b), enquanto os indicadores de eficácia e equidade escolar se basearam no modelo (c).

Para minimizar as diferenças presentes entre as UF, foram tomadas algumas precauções:

- Ajustamos o modelo independentemente para cada UF;

- Para definir o indicador de qualidade, utilizamos os efeitos aleatórios das escolas ao invés do intercepto propriamente dito;

- Realizamos as análises independentemente para dois grupos de estados (ricos e pobres).

Os pacotes R utilizados para modelagem foram "nlme" e "multilevel", especialmente a função "lme()", que se fundamenta na estrutura descrita por Lindstrom e Bates (1988). Também foram realizados testes com o pacote "lme4", mas ele se mostrou menos robusto quando se adicionou a variável de peso.

\subsection{Identificação e comparação de escolas eficazes}

Em virtude das limitações dos dados disponíveis, a definição de Murillo (2003) foi adaptada. $\mathrm{O}$ valor adicionado precisou ser substituído pelo desempenho contextualizado: o efeito aleatório no nível da escola ( $\mathrm{u}_{\mathrm{ok}}$ ). A equidade foi definida como o inverso da inclinação: o efeito aleatório do coeficiente da variável "escolaridade familiar" $\left(\mathrm{u}_{1 \mathrm{k}}\right)$ multiplicado por -1 . Trata-se da equidade dentro da escola. E o desenvolvimento integral (c) foi definido como a capacidade de produzir bons resultados em todos os indicadores disponíveis, no caso, estamos limitados a apenas dois indicadores de resultado 2 , as notas de Matemática e Língua Portuguesa.

Em suma, foram utilizadas as seguintes características para definir as escolas eficazes aplicando-se a definição de Murillo (2003) aos dados da Prova Brasil.

- Desempenho contextualizado acima da mediana em Matemática.

- Desempenho contextualizado acima da mediana em Língua Portuguesa. 
- Equidade intraescolar acima da mediana em Matemática.

- Equidade intraescolar acima da mediana em Língua Portuguesa.

Foram identificados dois tipos de escolas eficazes: o Grupo A inclui todas as escolas que atendem simultaneamente aos dois primeiros critérios 1 e 2 , enquanto no Grupo B elas atendem aos quatro critérios.

A comparação entre as escolas de cada grupo e as demais foi realizada com o Teste de Wilcoxon (Wilcoxon rank sum test) unicaudal com correção de continuidade $(\mathrm{p}<0,05)$. Foram comparadas 44 características (variáveis dicotômicas e ordinais) das escolas, provenientes de variáveis do Saeb 2011. O teste foi aplicado, para cada variável, seis vezes: três para o Grupo A e outras três para o Grupo B. Em cada grupo, o teste foi aplicado: 1) no conjunto das seis UF; 2) nas três UF de menor renda per capita; 3) nas três UF de maior renda per capita. Para cada caso foram aplicados dois testes de Wilcoxon pois, sendo unicaudal, as duas caudas precisam ser testadas independentemente.

Vale destacar uma limitação metodológica deste estudo. A inexistência de dados longitudinais em nível nacional dificulta uma estimação mais precisa da efetiva contribuição de cada escola para seus alunos, o valor adicionado (Martínez-Arias, 2009; Thomas, 1998). Não se trata, é importante esclarecer, de uma limitação gratuita, mas sim de respeito à privacidade do aluno. Tal limitação também exclui a possibilidade de se estimar a perdurabilidade dos efeitos da escola, motivo pelo qual não utilizamos o modelo mais recente de eficácia escolar (Martínez-Garrido e Murillo, 2016).

\section{Resultados}

\subsection{Equidade ao longo da educação básica}

O quadro 2 mostra que um ano a mais na escolaridade dos pais está associado a um acréscimo de 3 pontos na prova do Saeb dos alunos do $5^{\circ}$ ano. Dado que a escolaridade familiar vai de zero a 15 anos, isso significaria um acréscimo de até 45 pontos, comparando-se os dois extremos. Contudo, para os alunos da $3^{a}$ série do Ensino Médio, um ano corresponde a 4 pontos, chegando a um máximo de 60 pontos que poderiam ser decorrentes de diferenças na escolaridade familiar. É importante ressaltar que a escolaridade dos pais é considerada, aqui, um proxy para o NSE do aluno.

Quadro 2. Influência da escolaridade dos pais na Educação Básica

\begin{tabular}{lccccc}
\hline & N ALUNOS & INTERCEPTO & $\begin{array}{c}\text { ESCOLARIDADE } \\
\text { DOS PAIS }\end{array}$ & R2 (\%) & P-VALOR \\
\hline $5^{\circ}$ ano EF & 3.134 .412 & 168,0 & 3,0 & 8,8 & $<0,001$ \\
$9^{\circ}$ ano EF & 3.005 .344 & 217,4 & 3,7 & 9,8 & $<0,001$ \\
$3^{\text {a }}$ série EM & 2.123 .107 & 238,8 & 4,1 & 11,2 & $<0,001$ \\
\hline
\end{tabular}

Fonte: Elaboração própria.

Resultados de três modelos lineares simples, tendo a nota em Língua Portuguesa como variável resposta e a escolaridade dos pais (em anos) como variável explicativa. Elaborado com base nos dados do SAEB 2011.

É esperado que o sistema escolar ajude a reduzir as desigualdades iniciais entre as crianças, compensando em alguma medida o efeito da família. Contudo, o que o quadro 2 sugere é que a importância do contexto familiar tende a aumentar ao longo da 
escolaridade, o que parece corroborar a ideia de que a escola reproduz desigualdades (Bourdieu e Passeron, 1990). Isto se observa tanto nos coeficientes da escolaridade dos pais quanto nos coeficientes de determinação dos modelos. Segundo nomenclatura do PISA (OECD, 2010), o gradiente socioeconômico (efeito da condição socioeconômica no desempenho educacional) apresenta, dentre outras, duas propriedades: a "força" do gradiente (coeficiente de determinação do modelo) e a "inclinação" da linha (coeficiente da variável socioeconômica). Sendo assim, o quadro 2 mostra que o gradiente socioeconômico aumenta ao longo da educação básica, tanto em termos "força" quanto "inclinação".

Não se pode, contudo, atribuir tal fenômeno à escola, até porque não dispomos de uma "sociedade sem escolas" semelhante à nossa para servir como referência de comparação. É possível que, sem a ação da escola, este aumento de iniquidade fosse ainda maior. De todo modo, há outras hipóteses para explicar este fenômeno. É possível, por exemplo, que as etapas finais da escolarização sejam mais difíceis de serem cumpridas sem pais muito escolarizados, em virtude de um caráter autoreferente e cumulativo da cultura escolar. Também é possível que haja alguma diferença significativa entre as populações dos três recortes de alunos e respectivas famílias, embora esta hipótese seja pouco provável, visto que há no máximo sete anos de diferença entre as séries analisadas. De qualquer forma, este aumento da iniquidade ao longo da Educação Básica confirma necessidade de se priorizar a equidade no sistema educacional brasileiro, especialmente nas etapas finais.

\subsection{Eficácia escolar no $9^{\circ}$ ano do Ensino fundamental}

A análise multinível em três níveis (aluno, turma, escola) mostrou que tanto o nível da turma quanto o da escola influenciam o desempenho escolar, em magnitudes semelhantes: o coeficiente de Correlação Intra Classe no nível da turma variou entre $2 \%$ e $8 \%$, enquanto no nível da escola entre $2 \%$ e $12 \%$.

O quadro 3 mostra os coeficientes fixos estimados para cada um dos seis estados. Mesmo controlando as diferenças de NSE da escola, o NSE individual (escolaridade dos pais) se mostrou significativamente associado ao resultado do aluno. Além disso, a influência do NSE individual tende a ser maior nos estados mais ricos, sugerindo menor equidade nos mesmos.

Tendo identificado uma associação significativa entre o NSE individual e desempenho escolar, o próximo passo é verificar se tal associação é semelhante em todas as escolas, ou se há algumas que conseguem trabalhar de forma mais equitativa do que outras. Observando os intervalos de confiança dos coeficientes aleatórios dos modelos multinivel (quadro 4), nota-se que nenhum chega até zero, evidenciando a significância da equidade intraescolar. Em outras palavras, há escolas mais equitativas do que outras.

\subsection{Relações entre indicadores}

A partir dos resultados das provas e das informações dos questionários, foram calculadas, para cada uma das 11.810 escolas, as seguintes variáveis:

- Desempenho contextualizado (indicador de qualidade), estimados através de modelagem multinível.

- Inclinação do gradiente socioeconômico (indicador de equidade intraescolar), estimados através de modelagem multinível. 
- Média da nota de prova.

- Média da escolaridade familiar.

- Coeficiente de Gini da nota de prova.

- Coeficiente de Gini da escolaridade familiar.

Quadro 3. Coeficientes fixos dos modelos multinível

\begin{tabular}{|c|c|c|c|c|}
\hline ESTADO & Prova & INTERCEPTO & $\begin{array}{l}\text { NSE DA } \\
\text { ESCOLA } \\
\end{array}$ & $\begin{array}{c}\text { NSE DO ALUNO } \\
\text { (ESCOLARIDADE DOS PAIS) }\end{array}$ \\
\hline & $\mathrm{L}$ & $\begin{array}{c}224.02 \\
(221.34 \mid 226.71)\end{array}$ & $\begin{array}{c}4.93 \\
(3.34 \mid 6.52)\end{array}$ & $\begin{array}{c}4.26 \\
(3.66 \mid 4.85)\end{array}$ \\
\hline & M & $\begin{array}{c}229.33 \\
(226.5 \mid 232.17)\end{array}$ & $\begin{array}{c}3.83 \\
(2.17 \mid 5.48)\end{array}$ & $\begin{array}{c}5.29 \\
(4.72 \mid 5.86)\end{array}$ \\
\hline & $\mathrm{L}$ & $\begin{array}{c}246.34 \\
(244.72 \mid 247.96)\end{array}$ & $\begin{array}{c}7.36 \\
(6.45 \mid 8.27)\end{array}$ & $\begin{array}{c}5.39 \\
(5.01 \mid 5.77)\end{array}$ \\
\hline & M & $\begin{array}{c}247.69 \\
(245.67 \mid 249.71)\end{array}$ & $\begin{array}{c}4.74 \\
(3.62 \mid 5.86)\end{array}$ & $\begin{array}{c}5.67 \\
(5.29 \mid 6.05)\end{array}$ \\
\hline & $\mathrm{L}$ & $\begin{array}{c}239.71 \\
(238.02 \mid 241.4)\end{array}$ & $\begin{array}{c}10.67 \\
(9.84 \mid 11.5)\end{array}$ & $\begin{array}{c}4.86 \\
(4.42 \mid 5.3)\end{array}$ \\
\hline & M & $\begin{array}{c}238.42 \\
(236.62 \mid 240.23)\end{array}$ & $\begin{array}{c}9.15 \\
(8.27 \mid 10.03)\end{array}$ & $\begin{array}{c}4.71 \\
(4.28 \mid 5.15)\end{array}$ \\
\hline & $\mathrm{L}$ & $\begin{array}{c}249.14 \\
(248.44 \mid 249.83)\end{array}$ & $\begin{array}{c}5.73 \\
(5.04 \mid 6.42)\end{array}$ & $\begin{array}{c}7.28 \\
(6.89 \mid 7.68)\end{array}$ \\
\hline & M & $\begin{array}{c}260.04 \\
(259.24 \mid 260.85) \\
\end{array}$ & $\begin{array}{c}5.49 \\
(4.71 \mid 6.28) \\
\end{array}$ & $\begin{array}{c}7.28 \\
(6.89 \mid 7.66) \\
\end{array}$ \\
\hline & $\mathrm{L}$ & $\begin{array}{c}245.21 \\
(244.85 \mid 245.58)\end{array}$ & $\begin{array}{c}4.55 \\
(4.2 \mid 4.9)\end{array}$ & $\begin{array}{c}6.41 \\
(6.24 \mid 6.57)\end{array}$ \\
\hline & M & $\begin{array}{c}249.28 \\
(248.87 \\
\end{array}$ & $\begin{array}{c}4.22 \\
(3.83 \\
\end{array}$ & $\begin{array}{c}6.21 \\
(6.05 \mid 6.36) \\
\end{array}$ \\
\hline & $\mathrm{L}$ & $\begin{array}{c}249.71 \\
(249.1 \mid 250.33)\end{array}$ & $\begin{array}{c}5.1 \\
(4.55 \mid 5.65)\end{array}$ & $\begin{array}{c}5.52 \\
(5.18 \mid 5.86)\end{array}$ \\
\hline & M & $\begin{array}{c}260.42 \\
(259.67 \mid 261.16)\end{array}$ & $\begin{array}{c}5.43 \\
(4.77 \mid 6.09)\end{array}$ & $\begin{array}{c}5.06 \\
(4.72 \mid 5.41)\end{array}$ \\
\hline
\end{tabular}

Note: As provas são: $\mathrm{L}=$ Linguagem e Português; $\mathrm{M}=$ Matemática. Os números entre parênteses representam o intervalo de confiança de $95 \%$.

Fonte: Elaborado pelo autor com base nos dados da Prova Brasil 2011, $9^{\circ}$ ano do Ensino Fundamental.

Nota-se no quadro 5 que há considerável correlação negativa entre duas características desejáveis em uma escola eficaz $(r=-0,58)$, sugerindo que é preciso valorizar ambas para reduzir o risco de uma sobrepor-se à outra. Com efeito, trata-se de um Trade Off entre qualidade e equidade, que não se verifica entre qualidade e desigualdade (Gini). Algo semelhante, embora menos intenso $(r=-0,35)$, foi observado entre a equidade e a média da escola propriamente dita. 
Quadro 4. Variância dos efeitos aleatórios dos modelos multinivel

\begin{tabular}{|c|c|c|c|c|c|}
\hline $\mathbf{M}$ & $\mathbf{P}$ & $\begin{array}{l}\text { VARIÂNCIA: } \\
\text { RESÍDUOS }\end{array}$ & $\begin{array}{l}\text { VARIÂNCIA: } \\
\text { ESCOLAS } \\
\end{array}$ & $\begin{array}{l}\text { VARIÂNCIA: } \\
\text { TURMAS } \\
\end{array}$ & $\begin{array}{c}\text { VARIÂNCIA: } \\
\text { NSE } \\
\end{array}$ \\
\hline O & $\mathrm{L}$ & $\begin{array}{c}2164.08 \\
(2129.22 \mid 2199.51)\end{array}$ & $\begin{array}{c}56.18 \\
(38.28 \mid 82.45)\end{array}$ & $\begin{array}{c}192.43 \\
(168.77 \mid 219.41)\end{array}$ & \\
\hline O & $\mathrm{M}$ & $\begin{array}{c}2214.85 \\
(2179.17 \mid 2251.11)\end{array}$ & $\begin{array}{c}77.85 \\
(57.07 \mid 106.19)\end{array}$ & $\begin{array}{c}180.07 \\
(157.27 \mid 206.17)\end{array}$ & \\
\hline 1 & $\mathrm{~L}$ & $\begin{array}{c}2127.4 \\
(2089.85 \mid 2165.62)\end{array}$ & $\begin{array}{c}58.84 \\
(39.9 \mid 86.77)\end{array}$ & $\begin{array}{c}170.32 \\
(146.26 \mid 198.35)\end{array}$ & $\begin{array}{c}6.84 \\
(2.63 \mid 17.81)\end{array}$ \\
\hline 1 & $\mathrm{M}$ & $\begin{array}{c}2174.45 \\
(2136.45 \mid 2213.13) \\
\end{array}$ & $\begin{array}{c}86.46 \\
(64.11 \\
\end{array}$ & $\begin{array}{c}156.32 \\
(134.79 \mid 181.28) \\
\end{array}$ & $\begin{array}{c}4.31 \\
(1.85 \\
\end{array}$ \\
\hline O & $\mathrm{L}$ & $\begin{array}{c}1891.42 \\
(1873.71 \mid 1909.3)\end{array}$ & $\begin{array}{c}152.79 \\
(135.68 \mid 172.06)\end{array}$ & $\begin{array}{c}120.12 \\
(109.02 \mid 132.35)\end{array}$ & \\
\hline O & $\mathrm{M}$ & $\begin{array}{c}1998.35 \\
(1979.63 \mid 2017.25)\end{array}$ & $\begin{array}{c}213.84 \\
(190.98 \mid 239.42)\end{array}$ & $\begin{array}{c}141.98 \\
(128.98 \mid 156.29)\end{array}$ & \\
\hline 1 & $\mathrm{~L}$ & $\begin{array}{c}1892.28 \\
(1872.14 \mid 1912.64)\end{array}$ & $\begin{array}{c}100.01 \\
(85.49 \mid 116.99)\end{array}$ & $\begin{array}{c}108.99 \\
(97.44 \mid 121.92)\end{array}$ & $\begin{array}{c}8.07 \\
(4.76 \mid 13.69)\end{array}$ \\
\hline 1 & M & $\begin{array}{c}1977.94 \\
(1956.93 \mid 1999.18) \\
\end{array}$ & $\begin{array}{c}191.03 \\
(168.31 \mid 216.81) \\
\end{array}$ & $\begin{array}{c}133.91 \\
(120.13 \mid 149.28) \\
\end{array}$ & $\begin{array}{c}7 \\
(4.16 \mid 11.79) \\
\end{array}$ \\
\hline $\mathrm{O}$ & $\mathrm{L}$ & $\begin{array}{c}1937.59 \\
(1914.29 \mid 1961.18)\end{array}$ & $\begin{array}{c}233.31 \\
(206.68 \mid 263.37)\end{array}$ & $\begin{array}{c}94.3 \\
(81.15 \mid 109.57)\end{array}$ & \\
\hline O & $\mathrm{M}$ & $\begin{array}{c}1966.17 \\
(1942.52 \mid 1990.1)\end{array}$ & $\begin{array}{c}229.3 \\
(202.82 \mid 259.25)\end{array}$ & $\begin{array}{c}89.57 \\
(76.55 \mid 104.81)\end{array}$ & \\
\hline 1 & $\mathrm{~L}$ & $\begin{array}{c}1926.34 \\
(1900.59 \mid 1952.44)\end{array}$ & $\begin{array}{c}89.51 \\
(73.59 \mid 108.88)\end{array}$ & $\begin{array}{c}86.83 \\
(73.66 \mid 102.36)\end{array}$ & $\begin{array}{c}8.19 \\
(4.75 \mid 14.12)\end{array}$ \\
\hline 1 & $\mathrm{M}$ & $\begin{array}{c}1953.17 \\
(1927.11 \\
(1979.59)\end{array}$ & $\begin{array}{c}118.26 \\
(99.08 \\
\end{array}$ & $\begin{array}{c}83.33 \\
(69.81 \mid 99.47) \\
\end{array}$ & $\begin{array}{c}7.74 \\
(4.69 \mid 12.77) \\
\end{array}$ \\
\hline $\mathrm{O}$ & $\mathrm{L}$ & $\begin{array}{c}2104.23 \\
(2084.13 \mid 2124.53)\end{array}$ & $\begin{array}{c}172.21 \\
(156.19 \mid 189.88)\end{array}$ & $\begin{array}{c}93.17 \\
(83.18 \mid 104.36)\end{array}$ & \\
\hline $\mathrm{O}$ & $\mathrm{M}$ & $\begin{array}{c}1933.27 \\
(1914.79 \mid 1951.92)\end{array}$ & $\begin{array}{c}266.44 \\
(244.96 \mid 289.82)\end{array}$ & $\begin{array}{c}99.09 \\
(88.91 \mid 110.45)\end{array}$ & \\
\hline 1 & $\mathrm{~L}$ & $\begin{array}{c}2069.4 \\
(2047.65 \mid 2091.38)\end{array}$ & $\begin{array}{c}109.54 \\
(96.73 \mid 124.04)\end{array}$ & $\begin{array}{c}90.19 \\
(79.79 \mid 101.94)\end{array}$ & $\begin{array}{c}5.35 \\
(2.4 \mid 11.91)\end{array}$ \\
\hline 1 & $\mathrm{M}$ & $\begin{array}{c}1886.6 \\
(1866.83 \mid 1906.57)\end{array}$ & $\begin{array}{c}211.79 \\
(193 \mid 232.41) \\
\end{array}$ & $\begin{array}{c}93.29 \\
(82.78 \mid 105.13)\end{array}$ & $\begin{array}{c}9.52 \\
(6.64 \mid 13.65)\end{array}$ \\
\hline O & $\mathrm{L}$ & $\begin{array}{c}1991.32 \\
(1969.9 \mid 2012.97)\end{array}$ & $\begin{array}{c}172.63 \\
(155.46 \mid 191.69)\end{array}$ & $\begin{array}{c}51.04 \\
(43.27 \mid 60.21)\end{array}$ & \\
\hline O & $\mathrm{M}$ & $\begin{array}{c}1879.99 \\
(1859.77 \mid 1900.43)\end{array}$ & $\begin{array}{c}228.59 \\
(207.53 \mid 251.8)\end{array}$ & $\begin{array}{c}45.7 \\
(38.48 \mid 54.27)\end{array}$ & \\
\hline 1 & $\mathrm{~L}$ & $\begin{array}{c}1938.85 \\
(1916.37 \mid 1961.58)\end{array}$ & $\begin{array}{c}98.66 \\
(86.64 \mid 112.35)\end{array}$ & $\begin{array}{c}44.86 \\
(37.08 \mid 54.26)\end{array}$ & $\begin{array}{c}6.81 \\
(4.14 \mid 11.2)\end{array}$ \\
\hline 1 & $\mathrm{M}$ & $\begin{array}{c}1824.68 \\
(1803.52 \mid 1846.09) \\
\end{array}$ & $\begin{array}{c}157.49 \\
(141.23 \mid 175.63) \\
\end{array}$ & $\begin{array}{c}41.5 \\
(34.03 \mid 50.61) \\
\end{array}$ & $\begin{array}{c}7.23 \\
(4.51 \mid 11.57) \\
\end{array}$ \\
\hline O & $\mathrm{L}$ & $\begin{array}{c}2434.87 \\
(2425.2 \mid 2444.57)\end{array}$ & $\begin{array}{c}156.93 \\
(148.44 \mid 165.9)\end{array}$ & $\begin{array}{c}130.55 \\
(125.74 \mid 135.55)\end{array}$ & \\
\hline O & $\mathrm{M}$ & $\begin{array}{c}2279.04 \\
(2269.99 \mid 2288.13)\end{array}$ & $\begin{array}{c}199.5 \\
(189.54 \mid 209.99)\end{array}$ & $\begin{array}{c}121.33 \\
(116.84 \mid 125.99)\end{array}$ & \\
\hline 1 & $\mathrm{~L}$ & $\begin{array}{c}2370.95 \\
(2360.68 \mid 2381.25)\end{array}$ & $\begin{array}{c}105.76 \\
(99.2 \mid 112.75)\end{array}$ & $\begin{array}{c}120.55 \\
(115.7 \mid 125.61)\end{array}$ & $\begin{array}{c}6.79 \\
(5.57 \mid 8.27)\end{array}$ \\
\hline 1 & $\mathrm{M}$ & $\begin{array}{c}2220.2 \\
(2210.55 \mid 2229.89)\end{array}$ & $\begin{array}{c}155.67 \\
(147.31 \mid 164.52)\end{array}$ & $\begin{array}{c}111.32 \\
(106.81 \mid 116.02)\end{array}$ & $\begin{array}{c}6.06 \\
(4.79 \mid 7.66)\end{array}$ \\
\hline
\end{tabular}

Note: $\mathrm{UF}=$ Unidade Federativa; $\mathrm{M}=$ Modelo; $\mathrm{P}=$ Prova. Os modelos são: $0=$ Modelo Nulo; $1=$ Modelo de Coeficientes Aleatórios utilizado na estimação dos indicadores escolares. Os números entre parênteses representam o intervalo de confiança de $95 \%$.

Fonte: Elaborado com base na Prova Brasil 2011, $9^{\circ}$ ano do Ensino Fundamental. 
Quadro 5. Matriz de correlação entre os indicadores escolares

\begin{tabular}{|c|c|c|c|c|c|}
\hline & $\begin{array}{c}\text { DESEMPENHO } \\
\text { CONTEXTUALIZADO }\end{array}$ & $\begin{array}{c}\text { EQUIDADE } \\
\text { INTRAESCOLAR }\end{array}$ & Prova* & $\begin{array}{l}\text { ESCOLARIDADE } \\
\text { FAMILIAR* }\end{array}$ & Prova** \\
\hline $\begin{array}{l}\text { Equidade } \\
\text { intraescolar }\end{array}$ & $-0,58$ & & & & \\
\hline Prova* & 0,65 & $-0,35$ & & & \\
\hline $\begin{array}{l}\text { Escolaridade } \\
\text { familiar* }\end{array}$ & 0,05 & $-0,02$ & 0,51 & & \\
\hline Prova ** & $-0,12$ & 0,07 & $-0,04$ & 0,25 & \\
\hline $\begin{array}{l}\text { Escolaridade } \\
\text { familiar** }\end{array}$ & $-0,09$ & 0,05 & $-0,10$ & 0,04 & 0,93 \\
\hline
\end{tabular}

Note: *Média. **Gini.

Fonte: Prova Brasil 2011, $9^{\circ}$ ano do Ensino fundamental.

Como esperado, a média da escola na prova apresenta considerável correlação com o desempenho contextualizado $(r=0,65)$ e a escolaridade familiar média $(r=0,51)$. Além disso, a alta correlação entre os dois coeficientes Gini $(r=0,93)$ significa que as escolas cujos pais apresentam escolaridade muito desigual tendem a apresentar resultados mais desiguais nas provas dos filhos.

O que buscamos, aqui, é justamente identificar escolas que conseguem romper com este ciclo vicioso da reprodução educacional intergeracional. Escolas capazes de promover mudanças no sentido da consolidação da democracia.

\subsection{Perfil das escolas selecionadas}

Do total de 11.810 escolas analisadas, 4.863 apresentaram desempenho contextualizado acima da mediana tanto na prova de Matemática quanto na prova de Língua Portuguesa. De maneira similar, 4.385 escolas apresentaram equidade intraescolar na metade superior, também nas duas provas. Considerando simultaneamente os dois critérios, o número de escolas se reduz para 732, o que está relacionado ao Trade Off entre desempenho contextualizado e equidade intraescolar.

Os dados do quadro 6 sugerem que as escolas selecionadas a partir dos critérios adotados (Grupos A e B) não se encontram em condições muito diferentes do total, como se nota no NSE da escola e na Escolaridade Familiar. Tal observação amplia as possibilidades de inferência na interpretação dos resultados.

Quadro 6. Principais características das escolas

\begin{tabular}{lccc}
\hline & TODAS & GRUPO A & GRUPO B \\
\hline Número de escolas & 11.810 & 4.863 & 732 \\
Proporção & $100 \%$ & $41 \%$ & $6 \%$ \\
NSE da escola (média) & 4,17 & 4,22 & 3,95 \\
NSE da escola (desvio padrão) & 1,18 & 1,18 & 1,28 \\
Escolaridade familiar em anos (média) & 6,78 & 6,92 & 6,67 \\
Escolaridade familiar em anos (desvio padrão) & 1,80 & 1,89 & 1,89 \\
Nota de MT (média) & 245,02 & 259,14 & 252,03 \\
Nota de MT (desvio padrão) & 21,67 & 18,78 & 15,57 \\
\hline
\end{tabular}

Note: Grupo A: escolas eficazes; Grupo B: escolas eficazes com equidade intraescolar.

Fonte: Elaborado pelo autor com base nos dados da Prova Brasil 2011, 9o ano do Ensino Fundamental. 
Tais grupos de escolas, é importante explicitar, poderiam ser ampliados ou reduzidos com alterações nos critérios utilizados. Não se trata, nesse sentido, de uma metodologia precisa de avaliação escolar que possa, por exemplo, servir de base para políticas de responsabilização e prestação de contas (accountability). Trata-se, diferentemente, de uma metodologia que permite investigar o fenômeno da eficácia escolar, comparando grupos de escolas.

\subsection{Características associadas às escolas eficazes}

Os resultados a seguir mostram quais características ocorreram com maior ou menor frequência nas escolas eficazes (Grupo $\mathrm{A}$ ou Grupo $\mathrm{B}$ ) em relação às restantes (significância com $\mathrm{p}<0,05$ ). Além disso, foram aplicados testes separados para as três UF mais ricas e as três mais pobres.

Nota-se, de um modo geral, que a inclusão da equidade intraescolar como critério de eficácia diminui bastante a capacidade de se identificar fatores associados, restando assim poucas características significativas no Grupo B. Há pelo menos duas hipóteses para explicar este fato: 1) é possível que o método utilizado seja pouco sensível a diferenças neste caso, já que foram poucas escolas selecionadas; 2) os resultados de fato mostram que o problema da equidade com qualidade é um grande desafio, ao menos no Brasil.

Nos dois casos, as características escolares significativamente associadas ao Grupo B ganham destaque enquanto elementos potencializadores de mudança social, especialmente onde há maior desigualdade socioeconômica. O quadro 7 confirma estudos anteriores mostrando que as questões de infraestrutura e recursos materiais ainda desempenham papel fundamental para a eficácia escolar no Brasil -o que vale tanto nas UF mais ricas quanto nas mais pobres.

Observando apenas a eficácia (Grupo A), todas as características materiais se mostraram significativas em todos os casos, com uma única exceção. Observando a eficácia com equidade (Grupo B), as características mais importantes foram os recursos disponíveis aos professores, como impressora, computador, internet e máquina copiadora, sugerindo importância da atividade docente mais personalizada e criativa. Em relação à infraestrutura, os dois aspectos mais significativos foram a segurança física da escola e o estado de conservação do pátio, sugerindo importância de um ambiente tranquilo e favorecedor de interações. O quadro 8 mostra que, levando em conta as seis diferentes situações, as variáveis mais associadas à eficácia escolar estão relacionadas ao salário e renda do diretor, sua escolaridade e sua experiência no cargo, não necessariamente sua idade.

O quadro 9 sugere certo perfil de professor das escolas eficazes: bem remunerado, bem formado e que utiliza diversos recursos pedagógicos. É curioso notar, nesse sentido, um uso do livro significativamente menor pelos professores das escolas eficazes das UF ricas. Todos os outros recursos foram mais utilizados pelos professores das escolas do Grupo A. Quando consideramos também a equidade (Grupo B) das seis UF ou das mais ricas, o único recurso mais utilizado pelos professores foi o datashow, sendo que nas UF pobres foi a copiadora. 
Quadro 7. Recursos materiais associados aos grupos

\begin{tabular}{|c|c|c|c|c|c|c|}
\hline & \multicolumn{3}{|c|}{ GRUPO A } & \multicolumn{3}{|c|}{ GRUPO B } \\
\hline & $\begin{array}{l}\mathrm{UF} \\
\text { todas }\end{array}$ & $\begin{array}{c}\mathrm{UF} \\
\text { pobres }\end{array}$ & $\begin{array}{l}\mathrm{UF} \\
\text { ricas }\end{array}$ & $\begin{array}{l}\mathrm{UF} \\
\text { todas }\end{array}$ & $\begin{array}{c}\mathrm{UF} \\
\text { pobres }\end{array}$ & $\begin{array}{l}\mathrm{UF} \\
\text { ricas }\end{array}$ \\
\hline $\begin{array}{l}\text { Há muros, grades ou cercas em } \\
\text { condições de garantir a segurança dos } \\
\text { alunos? }\end{array}$ & $\boldsymbol{\Delta}$ & $\boldsymbol{\Delta}$ & $\boldsymbol{\Delta}$ & $\Delta$ & & $\boldsymbol{\Delta}$ \\
\hline Banheiros: estado de conservação & $\Delta$ & $\boldsymbol{\Delta}$ & $\Delta$ & & & \\
\hline Pátio: estado de conservação & $\boldsymbol{\Delta}$ & $\boldsymbol{\Delta}$ & $\Delta$ & $\mathbf{\Delta}$ & & $\boldsymbol{\Delta}$ \\
\hline Salas de aula: estado de conservação & $\boldsymbol{\Delta}$ & & $\Delta$ & & & $\boldsymbol{\Delta}$ \\
\hline $\begin{array}{l}\text { Biblioteca: possui espaço para estudos } \\
\text { coletivos }\end{array}$ & $\boldsymbol{\Delta}$ & $\boldsymbol{\Delta}$ & $\Delta$ & & & \\
\hline $\begin{array}{l}\text { Biblioteca: a comunidade pode utilizar } \\
\text { o espaço e os livros. }\end{array}$ & $\Delta$ & $\boldsymbol{\Delta}$ & $\Delta$ & & & \\
\hline Computadores para administração & $\Delta$ & $\boldsymbol{\Delta}$ & $\Delta$ & & & \\
\hline Computadores para alunos & $\Delta$ & $\mathbf{\Delta}$ & $\Delta$ & & & $\mathbf{\Delta}$ \\
\hline Computadores para professores & $\Delta$ & $\boldsymbol{\Delta}$ & $\boldsymbol{\Delta}$ & & $\Delta$ & $\boldsymbol{\Delta}$ \\
\hline Internet para alunos & $\boldsymbol{\Delta}$ & $\mathbf{\Delta}$ & $\boldsymbol{\Delta}$ & & $\Delta$ & \\
\hline Internet para professores & $\Delta$ & $\mathbf{\Delta}$ & $\Delta$ & & $\Delta$ & $\boldsymbol{\Delta}$ \\
\hline Copiadora para professores & $\Delta$ & $\mathbf{\Delta}$ & $\Delta$ & $\boldsymbol{\Delta}$ & $\boldsymbol{\Delta}$ & \\
\hline Impressora para professores & $\boldsymbol{\Delta}$ & $\boldsymbol{\Delta}$ & $\Delta$ & $\Delta$ & $\boldsymbol{\Delta}$ & $\mathbf{\Delta}$ \\
\hline Retroprojetor para professores & $\Delta$ & $\Delta$ & $\Delta$ & & & \\
\hline
\end{tabular}

Note: As UF pobres são as três UF de menor renda per capita no Brasil, enquanto as UF ricas são as de maior renda per capita. Resultados sumarizados de testes Wilcoxon unicaudal, apenas variáveis significativas $(\mathrm{p}<0,05)$ : ' $\mathbf{\Lambda}^{\prime}=$ maior que nas escolas restantes; ' $\boldsymbol{\nabla}^{\prime}=$ menor que nas escolas restantes.

Fonte: Elaborado pelo autor com base nos dados da Prova Brasil 2011, $9^{\circ}$ ano do Ensino Fundamental.

Quadro 8. Características da direção associadas aos grupos

\begin{tabular}{|c|c|c|c|c|c|c|}
\hline & \multicolumn{3}{|c|}{ GRUPO A } & \multicolumn{3}{|c|}{ GRUPO B } \\
\hline & $\begin{array}{l}\mathrm{UF} \\
\text { todas }\end{array}$ & $\begin{array}{c}\mathrm{UF} \\
\text { pobres }\end{array}$ & $\begin{array}{l}\mathrm{UF} \\
\text { ricas }\end{array}$ & $\begin{array}{l}\mathrm{UF} \\
\text { todas }\end{array}$ & $\begin{array}{c}\mathrm{UF} \\
\text { pobres }\end{array}$ & $\begin{array}{l}\mathrm{UF} \\
\text { ricas }\end{array}$ \\
\hline Existe Conselho de Escola? & & $\boldsymbol{\Delta}$ & & & & $\Delta$ \\
\hline \multicolumn{7}{|l|}{ Diretor } \\
\hline Anos de experiência como diretor & $\Delta$ & $\Delta$ & $\Delta$ & & $\Delta$ & \\
\hline $\begin{array}{l}\text { Anos de experiência como diretor desta } \\
\text { escola }\end{array}$ & $\Delta$ & $\Delta$ & $\boldsymbol{\Delta}$ & & $\mathbf{\Delta}$ & \\
\hline Escolaridade & $\Delta$ & $\Delta$ & $\Delta$ & & & \\
\hline Idade & $\Delta$ & & & & & \\
\hline Renda Familiar & $\boldsymbol{\Delta}$ & $\mathbf{\Delta}$ & & & & $\mathbf{\Delta}$ \\
\hline Salário & $\Delta$ & $\Delta$ & & & & $\Delta$ \\
\hline
\end{tabular}

Note: Resultados sumarizados de testes Wilcoxon unicaudal, apenas variáveis significativas $(\mathrm{p}<0,05)$ : $^{\prime} \boldsymbol{\Delta}^{\prime}=$ maior que nas escolas restantes; ' $\boldsymbol{\nabla}^{\prime}=$ menor que nas escolas restantes.

Fonte: Elaborado pelo autor com base nos dados da Prova Brasil 2011, $9^{\circ}$ ano do Ensino Fundamental. 
Quadro 9. Características do professor associadas aos grupos

\begin{tabular}{|c|c|c|c|c|c|c|}
\hline & \multicolumn{3}{|c|}{ GRUPO A } & \multicolumn{3}{|c|}{ GRUPO B } \\
\hline & UF todas & UF pobres & UF ricas & UF todas & UF pobres & UF ricas \\
\hline Escolaridade & $\boldsymbol{\Delta}$ & $\Delta$ & $\Delta$ & & & \\
\hline Idade & & & & $\boldsymbol{\nabla}$ & & \\
\hline Salário & $\Delta$ & $\Delta$ & & & & $\boldsymbol{\Delta}$ \\
\hline Salário nesta escola & $\Delta$ & $\Delta$ & $\boldsymbol{\Delta}$ & & $\boldsymbol{\Delta}$ & $\Delta$ \\
\hline Uso de recursos & & & & & & \\
\hline Copiadora & $\boldsymbol{\Delta}$ & $\Delta$ & $\Delta$ & & $\Delta$ & \\
\hline Jornal & $\Delta$ & $\Delta$ & $\Delta$ & & & \\
\hline Livro & & & $\boldsymbol{\nabla}$ & & & $\boldsymbol{\nabla}$ \\
\hline Retroprojetor & $\Delta$ & $\Delta$ & $\boldsymbol{\Delta}$ & & & \\
\hline Slides / datashow & $\boldsymbol{\Delta}$ & $\boldsymbol{\Delta}$ & $\boldsymbol{\Delta}$ & $\Delta$ & & $\boldsymbol{\Delta}$ \\
\hline
\end{tabular}

Note: Resultados sumarizados de testes Wilcoxon unicaudal, apenas variáveis significativas $(\mathrm{p}<0,05)$ : $^{\mathbf{\Lambda}} \mathbf{\prime}$ = maior que nas escolas restantes; ' $\boldsymbol{\nabla}^{\prime}=$ menor que nas escolas restantes.

Fonte: Elaborado pelo autor com base nos dados da Prova Brasil 2011, $9^{\circ}$ ano do Ensino Fundamental.

Por fim, o quadro 10 mostra alguns aspectos da percepção dos professores quanto aos principais entraves do processo de ensino aprendizagem. Em todos os casos, os professores das escolas eficazes avaliaram como menos problemática a questão da insegurança física da escola-confirmando resultado do quadro 7 .

\section{Discussão}

O quadro 10 reúne um conjunto de resultados inesperado, que merece mais atenção: nas escolas eficazes e equitativas (Grupo B), o único recurso pedagógico mais utilizado pelos professores foi o datashow; nas mais UF pobres, foi a copiadora; e nas UF ricas houve maior uso de datashow e menor uso de livro. ${ }^{3}$ Tanto o datashow quanto a copiadora são ferramentas que pressupõe escolhas pessoais por parte do professor, realizando seleção de materiais e eventualmente criando alguns. Com o livro, isso não necessariamente acontece.

Com efeito, a comparação dos resultados de UF pobres e ricas sugere considerável importância das escolhas pessoais do docente em ambos os casos, porém adaptada a diferentes condições materiais e tecnológicas. $O$ teste $t$ confirma uma diferença significativa na disponibilidade do recurso $(\mathrm{p}<0,001)$ : nas UF ricas, $81,7 \%$ das escolas possuem datashow, enquanto nas UF pobres apenas $57,2 \%$.

3 Isso não significa que o livro é pouco utilizado. Pelo contrário, no quadro 1 pode-se conferir que o uso do livro entre professores varia entre $73 \%$ e $82 \%$, enquanto o uso de datashow varia entre $33 \%$ e $53 \%$. 
Quadro 10. Percepções dos professores sobre as causas dos problemas de aprendizagem

\begin{tabular}{|c|c|c|c|c|c|c|}
\hline & \multicolumn{3}{|c|}{ GRUPO A } & \multicolumn{3}{|c|}{ GRUPO B } \\
\hline & $\begin{array}{c}\text { UF } \\
\text { TODAS }\end{array}$ & $\begin{array}{c}\text { UF } \\
\text { POBRES }\end{array}$ & $\begin{array}{l}\text { UF } \\
\text { RICAS }\end{array}$ & $\begin{array}{c}\text { UF } \\
\text { TODAS }\end{array}$ & $\begin{array}{c}\text { UF } \\
\text { POBRES }\end{array}$ & $\begin{array}{l}\text { UF } \\
\text { RICAS }\end{array}$ \\
\hline $\begin{array}{l}\text { São decorrentes do meio em que o } \\
\text { aluno vive }\end{array}$ & $\boldsymbol{\nabla}$ & & $\boldsymbol{\nabla}$ & & & \\
\hline $\begin{array}{l}\text { São decorrentes do nível cultural dos } \\
\text { pais dos alunos }\end{array}$ & $\boldsymbol{\nabla}$ & & $\nabla$ & & & \\
\hline \multicolumn{7}{|l|}{$\begin{array}{l}\text { Estão relacionados à falta de } \\
\text { assistência e acompanhamento da } \\
\text { família nos deveres de casa e } \\
\text { pesquisas dos alunos }\end{array}$} \\
\hline $\begin{array}{l}\text { Estão vinculados à baixa autoestima } \\
\text { dos alunos }\end{array}$ & $\boldsymbol{\nabla}$ & & $\nabla$ & & & \\
\hline $\begin{array}{l}\text { Ocorrem devido ao desinteresse e falta } \\
\text { de esforço do aluno }\end{array}$ & $\boldsymbol{\Delta}$ & & $\boldsymbol{\Delta}$ & & & \\
\hline $\begin{array}{l}\text { São decorrentes da indisciplina dos } \\
\text { alunos em sala de aula }\end{array}$ & $\boldsymbol{\nabla}$ & $\boldsymbol{\nabla}$ & $\boldsymbol{\nabla}$ & & & \\
\hline $\begin{array}{l}\text { Ocorrem devido à falta de aptidão e } \\
\text { habilidades do aluno }\end{array}$ & $\nabla$ & $\boldsymbol{\nabla}$ & $\nabla$ & & & \\
\hline $\begin{array}{l}\text { Estão relacionados aos conteúdos } \\
\text { curriculares, que são inadequados às } \\
\text { necessidades dos alunos }\end{array}$ & $\boldsymbol{\nabla}$ & $\boldsymbol{\nabla}$ & $\nabla$ & & & \\
\hline $\begin{array}{l}\text { Estão relacionados ao não- } \\
\text { cumprimento do conteúdo curricular }\end{array}$ & $\nabla$ & $\nabla$ & $\nabla$ & & & \\
\hline $\begin{array}{l}\text { Ocorrem na escola devido à carência de } \\
\text { infra-estrutura física e/ou pedagógica }\end{array}$ & $\boldsymbol{\nabla}$ & $\boldsymbol{\nabla}$ & $\nabla$ & & & $\nabla$ \\
\hline $\begin{array}{l}\text { São decorrentes do ambiente de } \\
\text { insegurança física da escola }\end{array}$ & $\boldsymbol{\nabla}$ & $\boldsymbol{\nabla}$ & $\nabla$ & $\boldsymbol{\nabla}$ & $\nabla$ & $\nabla$ \\
\hline $\begin{array}{l}\text { Ocorrem na escola por oferecer poucas } \\
\text { oportunidades de desenvolvimento } \\
\text { das capacidades intelectuais do aluno }\end{array}$ & $\boldsymbol{\nabla}$ & $\boldsymbol{\nabla}$ & $\nabla$ & & & \\
\hline $\begin{array}{l}\text { Ocorrem devido ao baixo salário dos } \\
\text { professores, que gera insatisfação e } \\
\text { desestímulo para a atividade docente. }\end{array}$ & $\boldsymbol{\nabla}$ & & $\boldsymbol{\nabla}$ & & & \\
\hline $\begin{array}{l}\text { Relacionam-se à sobrecarga de } \\
\text { trabalho do(as) professores(as), } \\
\text { dificultando o planejamento e o } \\
\text { preparo das aulas. }\end{array}$ & $\boldsymbol{\nabla}$ & & $\nabla$ & & & \\
\hline
\end{tabular}

Note: Resultados sumarizados de testes Wilcoxon unicaudal, apenas variáveis significativas $(\mathrm{p}<0,05):^{\prime} \mathbf{\Lambda}^{\prime}=$ maior que nas escolas restantes; ' $\boldsymbol{\nabla}^{\prime}=$ menor que nas escolas restantes.

Fonte: Elaborado pelo autor com base nos dados da Prova Brasil 2011, $9^{\circ}$ ano do Ensino Fundamental.

De modo geral, os resultados do Grupo B sugerem certo perfil de professor que consegue ensinar bem e a todos, conciliando qualidade e equidade: um profissional bem remunerado, às vezes até mais jovem, capaz de lidar com recursos pedagógicos e que ensina de forma mais autoral, realizando escolhas durante o processo. Tal perspectiva corrobora estudos anteriores, como o já mencionado de Simielli (2015) e a síntese de meta análise realizada por Hattie (2009), juntando-se a outras evidências de que a atividade docente de excelência requer alto grau de investimento e condições para escolhas pessoais. A natureza do trabalho do educador, como do médico, o obriga a 
articular conhecimentos técnicos e um estilo pessoal de proceder, atuando entre a ciência e a arte. Nos termos de Anísio Teixeira (1977):

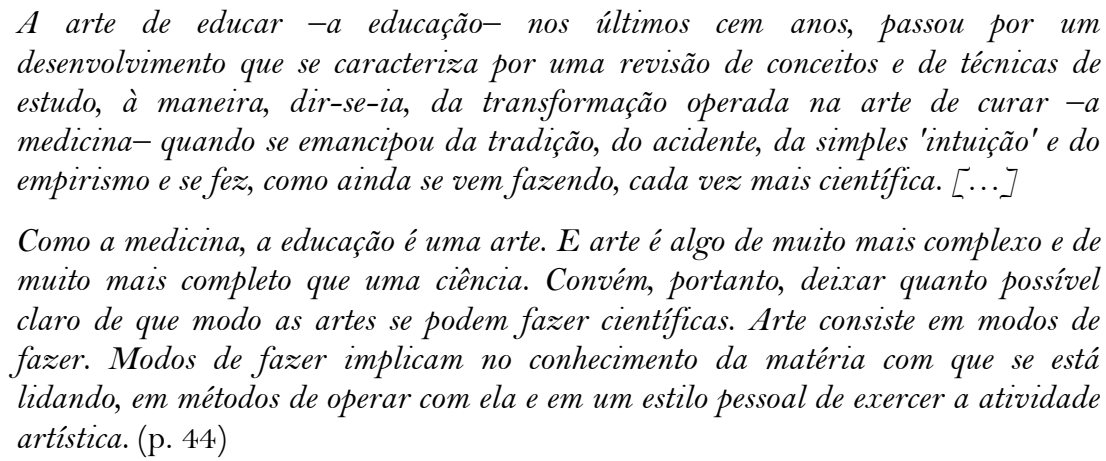

Nesse sentido, nossos resultados confirmam a ideia de que uma educação com excelência e equidade pressupõe investimento nos profissionais e certa autonomia dos educadores. É possível conceber políticas públicas em sentido oposto, com professores menos remunerados, porém acompanhados de materiais didáticos detalhados e monitoramento para responsabilização (accountability). Isso seria uma forma de se diminuir custos sem prejudicar a qualidade educacional - especialmente em contextos de menor NSE, em que os professores tendem a ser menos preparados. Nossos resultados, contudo, enfraquecem esta hipótese. Se o objetivo é ensinar a todos, rompendo o ciclo vicioso da reprodução da desigualdade, é necessário um professor com boa remuneração, com recursos pedagógicos e que faça escolhas, mesmo que eventualmente. Tanto em estados ricos quanto nos pobres. Infelizmente, na história brasileira, não é raro observar momentos de expansão educacional sem o devido aporte de recursos, como parece ter ocorrido logo após a Constituição de 1988 (Oliveira e Araujo, 2005) e entre 1995 e 2005 (Castro, 2007). Este tipo de política tende a reduzir a equidade no sistema educacional, comprometendo também sua excelência.

\section{Conclusão}

Foi identificada uma iniquidade crescente ao longo da Educação Básica. Cada ano adicional na escolaridade dos pais tende a acrescentar 3 pontos nas notas do Saeb no 5o ano do Ensino Fundamental, o que aumenta para 4 pontos ao final do Ensino Médio. Embora não se possa estimar com precisão a contribuição da escola para este quadro, ele mostra que a equidade de resultados é um desafio nas escolas públicas brasileiras, especialmente no final da Educação Básica.

Os resultados também evidenciam um Trade Off entre qualidade e equidade, confirmando estudos anteriores. Ou seja, quando se identifica as escolas de maior desempenho contextualizado, elas tendem a ser pouco equitativas internamente. $\mathrm{O}$ mesmo ocorre no nível dos estados.

Das 11.810 escolas avaliadas nos seis estados, identificamos 4.863 (41\%) instituições eficazes (Grupo A) e 732 (6\%) eficazes e equitativas (Grupo B). Os resultados mostram grande diversidade de fatores associados à eficácia escolar (Grupo A), incluindo infraestrutura, disponibilidade e uso de recursos pedagógicos, valorização do professor e do diretor, além do uso diversificado de recursos pedagógicos. Isto significa que, mesmo controlando o NSE da escola e do aluno, ainda há condições significativamente diferentes nas escolas eficazes, que poderiam ser alvo de políticas públicas específicas. 
Em relação ao Grupo B, as características associadas às escolas eficazes e equitativas sugerem que, para ensinar bem todos os alunos, é especialmente importante:

- O salário e a experiência do diretor.

- O salário e o trabalho criativo do professor.

- Disponibilidade de recursos pedagógicos para o professor.

- Manter um ambiente seguro com espaço de convivência.

Tais resultados confirmam achados anteriores, como a importância da criatividade docente para ensinar aqueles com mais dificuldade em aprender (Fernández Batanero, 2013), assim como a importância do uso variado de recursos didáticos (Román, 2008) e das condições laborais na escola (Martínez-Garrido e Murillo, 2016).

Em relação à investigação sobre eficácia escolar, este trabalho contribui como ampliação do estudo de Soares (2005), que utilizou os indicadores de equidade e qualidade separadamente, o que acabou gerando resultados de difícil interpretação para os indicadores de equidade. Levando em conta esta constatação, buscamos aqui utilizar o indicador de equidade atrelado ao indicador de qualidade, mesmo que de forma exploratória. Os resultados do Grupo B, interpretáveis e verossímeis, sugerem tal escolha foi bem-sucedida. Além disso, em termos teóricos, faz sentido atrelar a equidade de resultados aos próprios resultados. Afinal, de pouco vale um ensino apenas equitativo, pois tal objetivo poderia ser alcançado se todos os alunos aprendessem pouco, mas de forma homogênea.

Em relação às políticas públicas, nossa análise aponta a equidade de resultados como um desafio que precisa ser priorizado, pois embora seja um pressuposto para a democratização da qualidade educacional, a iniquidade permanece, chegando a aumentar com os anos de escolaridade. Além disso, a análise multinível sugere que políticas promotoras de equidade são especialmente importantes quando há valorização do desempenho escolar, como seria o caso de políticas de responsabilização (accountability). Afinal, foram raras as escolas que congregaram qualidade e equidade, ensinando bem e a todos. Traçando um perfil médio dessas escolas, observamos profissionais bem remunerados, diretores experientes, professores criativos, diversidade e disponibilidade de recursos pedagógicos, além de um ambiente seguro. Para que se possa de fato priorizar cada um destes fatores, é necessário (embora não suficiente) considerável investimento na educação, o que aponta no sentido oposto de políticas recentes no Brasil e em outros países ibero-americanos, voltadas para a redução de custos na educação pública.

Cabe ressaltar ainda algumas limitações do estudo e caminhos futuros. Em virtude da ausência de dados longitudinais no Saeb, não pudemos estimar o valor adicionado pela escola nem a perdurabilidade dos efeitos, o que limitou a aplicação do modelo de Martínez-Garrido e Murillo (2016). Além disso, o desenvolvimento integral foi abordado de forma bastante limitada, incluindo apenas duas medidas de resultado similares (as provas de matemática e língua portuguesa). Em estudos futuros, pode-se explorar o questionário do Saeb aplicado ao aluno em busca de indicadores sócio afetivos, como autoconceito e satisfação com a escola. Isto tornaria a metodologia de análise do Saeb mais fiel ao modelo proposto por Martínez-Garrido e Murillo (2016). 
Podemos agora responder as perguntas formuladas inicialmente:

A influência do nível socioeconômico familiar no desempenho dos alunos vai diminuindo ao longo da vida escolar?

Pelo contrário, as evidências sugerem que a diferença no desempenho entre alunos com pais de diferentes escolaridades (indicador do nível socioeconômico) só aumenta durante a Educação Básica. Não foi possível verificar em que medida a escola é responsável por este quadro, mas ele parece revelar um nó górdio no caminho da efetiva democratização da educação no Brasil.

Existem escolas que ensinam os alunos de forma mais equitativa do que outras?

Mesmo controlando o nível socioeconômico, há escolas mais e menos equitativas, como evidenciam os modelos multinivel.

Existem escolas que ensinam os alunos de forma equitativa e com qualidade?

Embora haja correlação negativa entre equidade e qualidade, foi possível encontrar 732 escolas $(6 \%)$ com indicadores acima da mediana em ambas as características, tanto na prova de Língua Portuguesa quanto Matemática, atendendo aos três critérios para uma escola eficaz.

É possivel identificar características associadas a estas escolas?

Sim, embora a introdução do indicador de equidade intraescolar diminua bastante o número de variáveis significativas identificadas. Tais escolas costumam apresentar: profissionais (professores e diretores) melhor remunerados do que as restantes; maior disponibilidade de recursos pedagógicos; uso mais diversificado de recursos pedagógicos; atuação mais criativa do professor; maior disponibilidade de computadores e internet para professores e alunos; ambiente mais seguro; condições melhores de infraestrutura.

Em que medida os dados do Saeb podem ser utilizados para avaliar a eficácia escolar?

Atualmente, os dados das escolas públicas de Ensino Fundamental podem gerar indicadores escolares de qualidade e equidade potencialmente interessantes, embora limitados, tal como exemplificado neste trabalho. Uma limitação é inexistência de dados censitários de escolas privadas e do Ensino Médio. Outra limitação é a inexistência de dados longitudinais, impossibilitando o uso de modelos de valor adicionado e a estimação da perdurabilidade dos efeitos da escola. Uma terceira limitação importante refere-se ao número reduzido de medidas de resultado (apenas as provas de Matemática e Português, e talvez algumas respostas do questionário), o que impossibilita uma avaliação adequada do quanto as escolas contribuem para o desenvolvimento integral dos alunos.

\section{Agradecimentos}

Agradeço à Maria Eugênia Ferrão pelas valiosas lições que deram base a este estudo, e também ao João Bacchetto e demais pesquisadores do Inep que contribuíram no debate sobre os dados preliminares. O presente trabalho foi realizado com apoio do $\mathrm{CNPq}$, Conselho Nacional de Desenvolvimento Científico e Tecnológico, Brasil. Bolsa de apoio durante Pós-Doutorado: CNPq, Conselho Nacional de Desenvolvimento Científico e Tecnológico, Brasil. 


\section{Referências}

Albernaz, A., Ferreira, F. e Franco, C. (2002). Qualidade e equidade no ensino fundamental brasileiro. Pesquisa E Planejamento Econômico, 32(3), 453-476.

Biondi, R. L. e Felício, F. (2007). Atributos escolares e o desempenho dos estudantes: Uma análise em painel dos dados do Saeb. Brasília: Instituto Nacional de Estudos e Pesquisas Educacionais Anísio Teixeira.

Bourdieu, P. e Passeron, J. (1990). Reproduction in education, society and culture. Londres: Sage Publications.

Castro, J. A. (2007). Financiamento e gasto público na educação básica no Brasil: 1995-2005. Educação E Sociedade, 28(100), 857-876. https://doi.org/10.1590/So10173302007000300011

Coleman, J. (1966). Equality of educational opportunity. Washington, DC: National Center for Educational Statistics.

Dewey, J. (2004). Democracy and education. Delhi: Aakar.

Fernández Batanero, J. M. (2013). Competencias docentes y educación inclusiva. Revista Electrónica de Investigación Educativa, 15(2), 82-99.

Ferrão, M. E. (2013). School effectiveness research findings in the Portuguese speaking countries: Brazil and Portugal. Educational Research for Policy and Practice, 13(1), 3-24. https://doi.org/10.1007/s10671-013-9151-7

Ferrão, M. E. e Fernandes, C. (2003). O efeito-escola e a mudança - dá para mudar? Evidências da investigação brasileira. REICE. Revista Iberoamericana sobre Calidad, Eficacia y Cambio em Educación, 1(1), 1-13.

Field, S., Kuczera, M. e Pont, B. (2007). No more failures: Ten steps to equity in education. París: OECD Publishing. https://doi.org/10.1787/9789264032606-en

Hattie, J. (2009). Visible learning: A synthesis of over 800 meta-analyses relating to achievement. Abingdon: Routledge. https://doi.org/10.1080/01443410903415150

IBGE. (2014). Estados. Recuperado de http://www.ibge.gov.br/estadosat/

Lindstrom, M. J. e Bates, D. M. (1988). Newton-Raphson and EM algorithms for linear mixedeffects models for repeated-measures data. Journal of the American Statistical Association, 83(404), 10-14. https://doi.org/10.1080/01621459.1988.10478693

Martínez-Arias, R. (2009). Usos, aplicaciones y problemas de los modelos de valor añadido en educación. Revista de Educación, 348, 217-250.

Martínez-Arias, R., Gaviria, J. L. e Castro, M. (2009). Concepto y evolución de los modelos de valor añadido en educación. Revista de Educación, 348, 15-45.

Martínez-Garrido, C. (2015). La investigación sobre Enseñanza Eficaz. Un estudio multinivel para Iberoamérica (Tesis doctoral). Madrid: UAM Ediciones.

Martínez-Garrido, C. e Murillo, F. J. (2013). El uso de los modelos multinivel en la investigación educativa. Estadísticas avanzadas para conocer y cambiar la educación en América Latina. En A. Salceido. Estadística en la investigación: Competencia transversal en la formación universitaria (p. 47-71). Caracas: Universidad Central de Venezuela.

Martínez-Garrido, C. e Murillo, F. J. (2016). Investigación iberoamericana sobre enseñanza eficaz. Revista Mexicana de Investigación Educativa, 21(69), 471-499. 
Mortimore, P. (1991). The nature and findings of research on school effectiveness in the primary sector. En S. Riddell e S. Brown (Eds.), School effectiveness research: Its messages for school improvement (pp. 9-19). Edinburgh: HMSO.

Murillo, F. J. (2003). Una panorámica de la investigación iberoamericana sobre eficacia escolar. REICE. Revista Iberoamericana sobre Calidad, Eficacia y Cambio en Educacion, 1(1), 1-14.

Murillo, F. J. (2008). Enfoque, situación y desafíos de la investigación sobre eficacia escolar en América Latina y el Caribe. En R. Blanco (Coord.), Eficacia escolar y factores asociados en América Latina y el Caribe (pp. 17-48). Santiago de Chile: UNESCO-LLECE.

OECD. (2010). PISA 2009 Results: Overcoming social background - equity in learning opportunities and outcomes. París: OECD Publishing.

Oliveira, R. P. e Araujo, G. C. (2005). Qualidade do ensino: Uma nova dimensão da luta pelo direito à educação. Revista Brasileira de Educação, 28, 5-23. https://doi.org/10.1590/S1413-24782005000100002

Raudenbush, S. W. e Willms, J. D. (1995). The estimation of school effects. Journal of Educational and Behavioral Statistics, 20(4), 307-321. https://doi.org/10.2307/1165304

Román, M. (2008). Investigación latinoamericana sobre enseñanza eficaz. En R. Blanco (Coord.), Eficacia escolar y factores asociados en América Latina y el Caribe (pp. 209-234). Santiago de Chile: UNESCO-LLECE

Sammons, P., Hillman, J. e Mortimore, P. (1995). Key characteristics of effective schools: A review of school effectiveness research. Londres: B \& MBC Distribution Services.

Simielli, L. E. R. (2015). Equidade educacional no Brasil: Análise das oportunidades educacionais em 2001 e 2011 (Tese doutorado). Escola de Administração de Empresas de São Paulo, São Paulo.

Soares-Neto, J. J., de Jesus, G. R., Karino, C. A. e Andrade, D. F. (2013). Uma escala para medir a infraestrutura escolar. Estudos em Avaliação Educacional, 24(54), $\quad$ 78-99. https://doi.org/10.18222/eae245420131903

Soares, J. F. (2005). Qualidade e eqüidade na educação básica brasileira: Fatos e possibilidades. Em VVAA., Os Desafios da Educação no Brasil (pp. 87-114). Rio de Janeiro: Nova Fronteira.

Soares, J. F. e Andrade, R. J. (2006). Nível socioeconômico, qualidade e equidade das escolas de Belo Horizonte. Ensaio: Avaliação e Políticas Públicas em Educação, 14(50), 107-134. https://doi.org/10.1590/So 104-40362006000100008

Teixeira, A. (1977). Educação e o mundo moderno. São Paulo: Ed. Nacional.

Thomas, S. (1998). Value-added measures of school effectiveness in the United Kingdom. Prospects, 28(1), 1-21. https://doi.org/10.1007/BF02737782

Travitzki, R., Calero, J. e Boto, C. (2014). What does the national high school exam (enem) tell brazilian society? Cepal Review, 113, 157-174. https://doi.org/10.18356/5db107a1-en

Waltenberg, F. D. e Vandenberghe, V. (2007). What does it take to achieve equality of opportunity in education?. An empirical investigation based on Brazilian data. Economics of Education Review, 26(6), 709-723. https://doi.org/10.1016/j.econedurev.2007.09.002 


\section{Breve CV do autor}

\section{Rodrigo Travitzki}

Doutor em Educação (Universidade de São Paulo, Brasil) com pós-doutorado em Métodos Quantitativos aplicados à Educação (Universidade da Beira Interior, Portugal). Atualmente iniciando o segundo Pós-Doutorado, pela Universidade São Francisco. Desenvolve pesquisas sobre políticas públicas, qualidade e equidade, avaliação educacional e psicometria. As pesquisas normalmente utilizem dado públicos, software libre e linguagem de programação R. Foi graduado em Ciências Biológicas e fez Mestrado em Filosofia. E professor de Ensino Médio desde 1999. Criador e mantenedor do portal de educação Rizomas.net. Integrate do Grupo de Estudos e Pesquisas em Avaliação Educacional (Gepave) da USP. ORCID ID: 0000-0002-0107-682X. Email: travitzki@usp.br 